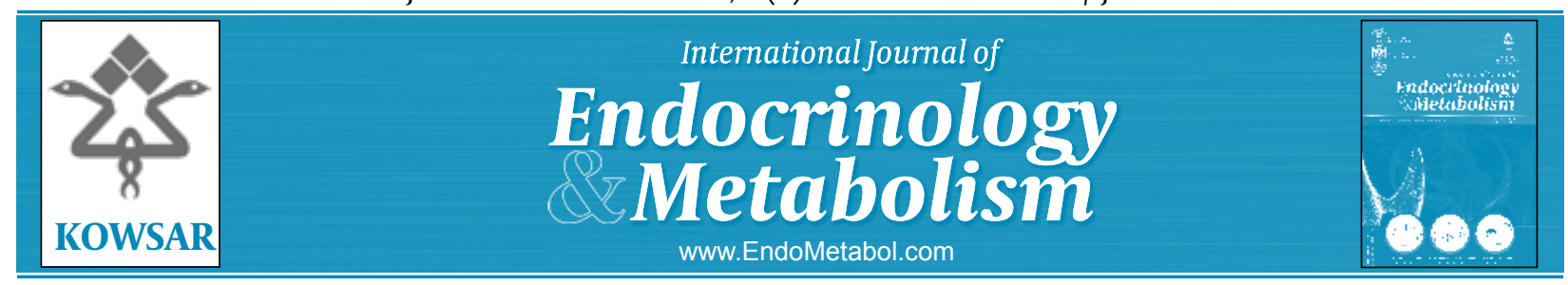

\title{
Tetralogy of Fallot Associated With Invasive Adrenocortical Tumor in an Adult Woman
}

\author{
Efren Martinez-Quintana ${ }^{1^{*}}$, Fayna Rodriguez-Gonzalez ${ }^{2}$, Maria Pino Alberiche-Ruano ${ }^{3}$, \\ Maria Soledad Martinez-Martin ${ }^{4}$ \\ ${ }^{1}$ Cardiology Service. Insular-Materno Infantil University Hospital, Las Palmas de Gran Canaria, Spain \\ 2 Ophthalmology Service. Dr. Negrín University Hospital, Las Palmas de Gran Canaria, Spain \\ ${ }^{3}$ Endocrinology Service. Insular-Materno Infantil University Hospital, Las Palmas de Gran Canaria, Spain \\ ${ }^{4}$ Anatomopathology Service. Insular-Materno Infantil University Hospital, Las Palmas de Gran Canaria, Spain
}

\begin{tabular}{l}
\hline A R T I C L E I N F O \\
Article type: \\
Case Report \\
\hline Article history: \\
Received: 10 Dec 2011 \\
Revised: 03 Feb 2012 \\
Accepted: 04 Feb 2012 \\
\hline
\end{tabular}

Keywords:

Tetralogy of Fallot

Adernal Cortex Neoplasms

Woman

\begin{abstract}
A B S T R A C T
Migration of cardiac neural crest cells into the pharyngeal arches and the pharyngeal and splanchnic mesoderm contributes to the development of the cardiac outflow tract. The adrenal cortex is derived from the splanchnic mesoderm. Neuroblastoma is more prevalent in patients with congenital heart disease than in the general population, because both originate from embryonal neural crest-derived cells. Similarly, and in light of recent embryological findings, abnormal development or migration of splanchnic mesoderm, possibly due to an underlying genetic defect, could contribute to the association of adrenocortical carcinoma and tetralogy of Fallot. We present the case of a cardiologically asymptomatic 49-year-old woman with total correction of tetralogy of Fallot in the first year of life.
\end{abstract}

Copyright $\odot 2012$ Kowsar Corp. All rights reserved.

- Implication for health policy/practice/research/medical education:

This study helps to understand the correlation between adrenocortical tumors and congenital heart disease, in order to rule out other clinical and genetic risk factors that could play an important role in these findings.

- Please cite this paper as:

Martinez-Quintana E, Rodriguez-Gonzalez F, Alberiche-Ruano MP, Martinez-Martin MS. Tetralogy of Fallot Associated with Invasive Adrenocortical Tumor in an Adult Woman. Int J Endocrinol Metab. 2012;10(2):503-5. DOI: 10.5812/ijem.3769

\section{Introduction}

The conditions considered in the differential diagnosis of retroperitoneal masses include benign tumors (e.g., lipoma, teratoma, paraganglioma, or nerve sheath tumors such as schwannomas and neurofibromas), malignant neoplasms (e.g., sarcomas such as liposarcoma, leiomyosarcoma, and malignant fibrous histiocytoma; extragonadal germ cell tumors; lymphoma; renal cell carcinomas; or testicular tumors), pyogenic abscesses, hematomas, or the Budd-Chiari syndrome. Most prima-

* Corresponding author: Efren Martinez-Quintana, Alcalde Ramirez Bethencourt,10, 3-A-35003, Las Palmas de Gran Canaria, Spain. Tel: +34-928373050, Fax: +34-928373050, E-mail: efrenmartinezquintana@yahoo.es

DOI:10.5812/ijem.3769

Copyright @2012 Kowsar Corp. All rights reserved. ry retroperitoneal tumors arise from one or more of the mesenchymal tissues of the retroperitoneum, and others are derived from neuroectodermal elements or from remnants of the urogenital ridge. At present, adrenocortical carcinoma, a rare and heterogeneous malignancy, has a poor prognosis, and its pathology is incompletely understood (1).

\section{Case Report}

We present the case of a cardiologically asymptomatic 49-year-old woman with total correction of tetralogy of Fallot in the first year of life, to relieve the right ventricular outflow tract stenosis and repair the ventricular septal defect with a Gore-Tex patch. The patient had no cardiovascular risk factors and was not undergoing 
any cardiac treatment. She was treated with progesterone during the last 3 years because of menstrual disorders. During the last few months, she complained of pain in her right flank, which was associated with weight loss. The patient had no history of hypertension, headaches, palpitations, facial flushing, hirsutism, or Cushing's syndrome.

Abdominal ultrasonography and computed tomography (Figure 1A) showed the presence of a heterogeneous solid mass measuring $9.3 \times 7.4 \mathrm{~cm}$ in the right adrenal gland; this mass was in contact with the liver, the right kidney, and the inferior vena cava. Echocardiography showed infiltration of the inferior vena cava with a tumor mass in the right atrium (Figure $1 B$ ) and an overriding aorta with no residual shunt in the repaired ven-

Figure 1. Computed Tomography Scan and Echocardiography Showing an Invasive Adrenocortical Carcinoma.

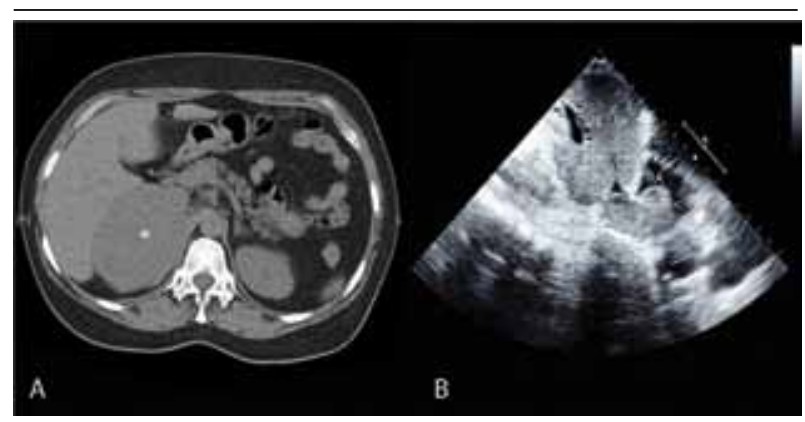

A: Cross-sectional computed tomography scan showing a heterogeneous, solid mass measuring $9.3 \times 7.4 \mathrm{~cm}$ in the right adrenal gland (asterisk), which was in close contact with the liver, the right kidney, and the inferior vena cava. B: Subcostal echocardiographic view showing infiltration of the inferior vena cava and a presumably metastatic mass in the right atrium (arrowhead). L: liver, RA: right atrium.

tricular septal defect (Figure 2A). Laboratory test results showed increased levels of free testosterone $(8.4 \mathrm{pcg} / \mathrm{ml}$; normal range, [0.7-3.6]) and 17-hydroxyprogesterone (3.5 $\mathrm{ng} / \mathrm{ml}$; normal range, [0.15-1.1]). The levels of urine and plasma metanephrines, urine free cortisol, dehydroepiandrosterone (DHEA), basal cortisol, adrenocorticotropic hormone (ACTH), aldosterone, and plasma renin activity were within the normal ranges.

Exploratory laparotomy and biopsies of the adrenal tumor revealed an adrenocortical carcinoma (Figure 2B), which showed positive immunohistochemical staining for vimentin, synaptophysin, and inhibin, and negative staining for cytokeratin, epithelial membranous antigen (EMA), and CD10. The adrenal glands are composed of 2 major components: the adrenal medulla and the adrenal cortex. The adrenal cortex is derived from the splanchnic mesoderm, and the adrenal medulla is derived from the ectodermal chromaffin cells from the neural crest (2). The adrenocortical carcinoma, which is derived from the adrenal cortex, is an aggressive cancer, with an annual incidence of 1-2 per million population and a bimodal distribution, with peaks of incidence at about 5 years of
Figure 2. Echocardiogram of the Corrected Tetralogy of Fallot and Biopsy of the Adrenocortical Carcinoma.
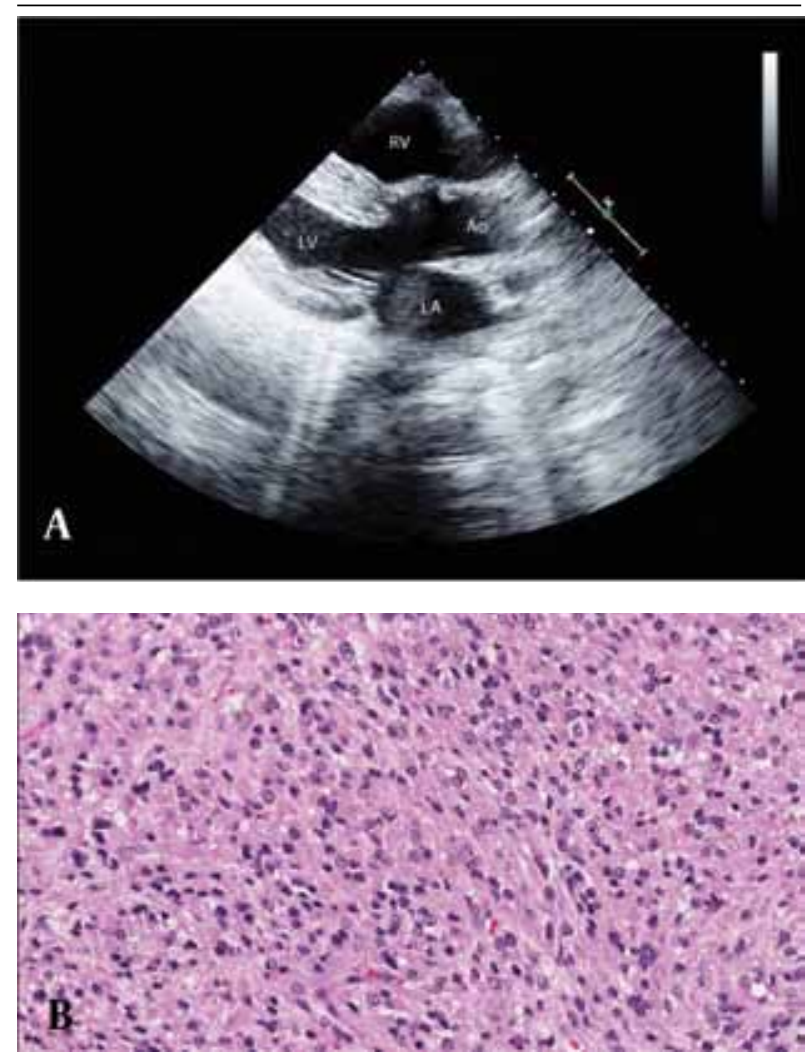

A: Long-axis echocardiographic view with an overriding aorta between both ventricles and an interventricular septal defect corrected with a patch (arrowhead). B: Hematoxylin and eosin stain showing an adrenocortical carcinoma with hyperchromasia, diffuse nuclear pattern of growth, and low mitotic activity. LA: left atrium, LV: left ventricle, RV: right ventricle; Ao: aorta. A color image is available in the online version of the article.

age and again at 40 to 50 years of age. Patients can present either with a hormonal syndrome or with general symptoms caused by an abdominal mass (3). Although the pathogenesis of adrenocortical carcinoma is unknown, smoking has been reported to be a risk factor in men, and use of oral contraceptives in women, especially before the age of 25 years. However, no associations were observed with alcohol use, height, weight, or diet patterns for either sex (4).

An overriding aorta is a congenital malalignment defect, wherein the aorta fails to wedge between the mitral and tricuspid atrioventricular valves. In this situation, the aorta, which should receive all the blood from the left ventricle, overrides the ventricular septum to a greater (double-outlet right ventricle) or lesser (tetralogy of Fallot) extent, thereby receiving a proportionate amount of blood from the right ventricle.

There are several case reports of patients with coexisting neuroblastoma and congenital heart defects (2, 5-7), suggesting that abnormal migration and development of neural crest cells may be a common link between cardiac malformations and congenital neuroblastomas. 
Some studies suggest a higher prevalence of congenital heart defects among patients with neuroblastoma than among the general population (8-10); however, others have shown no such association (11). Additionally, autopsy findings in a 21-year-old male with a complete transposition of the great arteries revealed that congenital heart defects (11) are associated with adrenocortical carcinomas (12). The association between neuroblastoma, an embryonal cancer of the postganglionic sympathetic nervous system that mostly arises from the adrenal medulla, and congenital heart disease is considered plausible because a neuroblastoma originates from embryonal neural crest-derived cells, and these neural crest-derived cells are also essential in cardiogenesis (9, 13). However, recent embryological findings show that the outflow ventricular tract, which is involved in tetralogy of Fallot, is elongated by not only cardiac neural crest cells but also cardiogenic cells from the pharyngeal and splanchnic mesoderm (14); therefore, it seems plausible that adrenocortical carcinoma is associated with overriding malalignment defects (probably due to an underlying genetic defect). However, further investigations should be conducted to understand the correlation between adrenocortical tumors and congenital heart disease, in order to rule out other clinical and genetic risk factors that could play an important role in these findings.

\section{Acknowledgments}

None declared.

\section{Financial Disclosure}

None declared.

\section{Funding/Support}

None declared.

\section{References}

1. Allolio B, Fassnacht M. Clinical review: Adrenocortical carcinoma: clinical update. J Clin Endocrinol Metab. 2006;91(6):2027-37.

2. Bellah R, D'Andrea A, Darillis E, Fellows KE. The association of congenital neuroblastoma and congenital heart disease. Is there a common embryologic basis? Pediatr Radiol.1989;19(2):119-21.

3. van Ditzhuijsen CI, van de Weijer R, Haak HR. Adrenocortical carcinoma. Neth J Med. 2007;65(2):55-60.

4. Hsing AW, Nam JM, Co Chien HT, McLaughlin JK, Fraumeni JF, Jr. Risk factors for adrenal cancer: an exploratory study. Int J Cancer. 1996;65(4):432-6.

5. Friedman DM, Dunnigan A, Magid MS. Coarctation of the aorta associated with neuroblastoma. Pediatr Cardiol.1998;19(6):480-1.

6. McElhinney DB, Reddy VM, Feuerstein BG, Marx GR, Hanley FL Intraoperative discovery of neuroblastoma in an infant with pulmonary atresia. Ann Thorac Surg. 1997;64(6):1827-9.

7. Rosti L, Lin AE, Frigiola A. Neuroblastoma and congenital cardiovascular malformations. Pediatrics. 1996;97(2):258-61.

8. Foulkes WD, Buu PN, Filiatrault D, Leclerc JM, Narod SA. Excess of congenital abnormalities in French-Canadian children with neuroblastoma: a case series study from Montreal. Med Pediatr Oncol.1997;29(4):272-9.

9. George RE, Lipshultz SE, Lipsitz SR, Colan SD, Diller L. Association between congenital cardiovascular malformations and neuroblastoma. J Pediatr. 2004;144(4):444-8.

10. Menegaux F, Olshan AF, Reitnauer PJ, Blatt J, Cohn SL. Positive association between congenital anomalies and risk of neuroblastoma. Pediatr Blood Cancer. 2005;45(5):649-55.

11. van Engelen K, Merks JH, Lam J, Kremer LC, Backes M, Baars MJ, et al. Prevalence of congenital heart defects in neuroblastoma patients: a cohort study and systematic review of literature. Eur J Pediatr. 2009;168(9):1081-90.

12. Roberts WC, Mason DT, Braunwald E. Survival to adulthood in a patient with complete transposition of the great vessels: including a note on the association of endocrine tumors with heart disease. Ann Intern Med. 1962;57:834-42.

13. Hutson MR, Kirby ML. Neural crest and cardiovascular development: a 20-year perspective. Birth Defects Res C Embryo Today. 2003;69(1):2-13.

14. Nakajima Y. Second lineage of heart forming region provides new understanding of conotruncal heart defects. Congenit Anom (Kyoto). 2010;50(1):8-14. 